\title{
MODIFIKASI MESIN PENGERING BIJI-BIJIAN DENGAN BAHAN BAKAR TEMPURUNG KELAPA
}

\section{MODIFICATION OF DRYLER MACHINERY MACHINE WITH COCONUT FUEL MATERIALS}

\author{
Asrianto 1), Jamaluddin 2), Kadirman 3) \\ 1)Alumni Program Studi Pendidikan Teknologi Pertanian, \\ 2) Dan 3) Dosen PTP FT UNM \\ Anto199491@gmail.com
}

\begin{abstract}
ABSTRAK
Penelitian ini bertujuan untuk mengetahui modifikasi mesin pengering menggunakan bahan bakar tempurung kelapa dan untuk mengetahui kebutuhan bahan bakar selama proses pengeringan biji-bijian (gabah padi). Penelitian ini merupakan penelitian rancang bangun. Prosedur pelaksanaan penelitian ini meliputi mendesain alat, pembuatan rangka, membuat rangkaian yang dapat digunakan oleh termometer dan kipas, serta pembuatan tungku. Selama proses penelitian parameter yang diamati adalah konsumsi bahan bakar yang digunakan selama proses pengeringan. Data penelitian diperoleh dari hasil pengujian alat mesin pengering. Teknik analisis data digunakan adalah teknik analisis deskriptif. Hasil penelitian menunjukkan bahwa konsumsi bahan bakar tempurung kelapa selama 4 jam pengeringan adalah $13,5 \mathrm{~kg}$. Hasil pengeringan dari gabah basah $18 \mathrm{~kg}$ menjadi 16,2 kg gabah kering dengan rata-rata kadar air kering 12,76 \%.
\end{abstract}

Kata kunci : mesin pengering, biji-bijian, tempurung kelapa

\section{ABSTRACT}

This study aims to determine the modification of the drying machine using coconut shell fuel and to determine the fuel requirements during the drying process of grain (rice grain). This research is a design research. The procedure for carrying out this research includes designing tools, making frames, making framework that can be used by thermometers and fans, as well as making furnaces. During the research process the parameters observed were the consumption of fuel used during the drying process. The research data was obtained from the results of the test machine dryer. Data analysis techniques used are descriptive analysis techniques. The results showed that consumption of coconut shell fuel for 4 hours of drying was $13.5 \mathrm{~kg}$. The drying result from wet grain is $18 \mathrm{~kg}$ to $16.2 \mathrm{~kg}$ dry grain with an average dry water content of $12.76 \%$.

Keywords: drying machine, grain, coconut shell

\section{PENDAHULUAN}

Kemajuan teknologi pascapanen di Indonesia menuntut tersedianya bahan baku yang bermutu tinggi untuk industri pengolahan hasil pertanian. Produk-produk pertanian yang berbentuk butiran, seperti: jagung, padi, kacang-kacangan, kopi, dan lain-lain memerlukan perhatian yang lebih serius, terutama pada proses pengawetan. Proses pengeringan memegang peranan penting dalam pengawetan suatu bahan. Proses pengeringan juga membantu mempermudah penyimpanan produk pertanian dalam rangka pendistribusian baik dalam skala domestik maupun ekspor. Proses 
pengeringan butiran bertujuan untuk mengurangi kandungan airnya sampai batas-batas tertentu, agar tidak terjadi kerusakan akibat aktivitas metabolisme oleh mikroorganisme (Mohsenin, 1980).

Pengeringan adalah suatu metode untuk mengeluarkan atau menghilangkan sebagian besar air dari suatu bahan melalui penerapan energi panas. Pengeringan dapat dilakukan dengan memanfaatkan energi surya (pengeringan alami) dan dapat juga dilakukan dengan menggunakan energi fosil, tenaga listrik maupun energi biomassa. Teknologi pemanfaatan energi fosil selama ini relatif tidak ramah lingkungan sehingga menimbulkan dampak negatif terhadap lingkungan. Sedangkan penggunaan tenaga listrik cukup efektif tetapi memerlukan biaya yang besar. Pertimbangan aspek lingkungan saja dalam pemilihan teknologi energi tidak cukup. Pemilihan teknologi harus didasarkan juga pada aspek ekonomi dan efisiensinya sehingga jenis teknologi energi yang dipilih adalah yang paling optimal ditinjau dari segi aspek ekonomi dan lingkungan (Anonim, 2002). Oleh karena itu, pemilihan energi biomassa selain karena ramah lingkungan, penggunaannya juga tidak memerlukan biaya yang besar dan mudah didapatkan.

Cara pengeringan dapat dilakukan secara konvensional maupun dengan menggunakan mesin pengering. Pengeringan secara konvensional dengan penjemuran bahan di bawah terik matahari mempunyai keunggulan tidak memerlukan keahlian khusus, tidak memerlukanbiaya yang besar dan kapasitas bahan yang dikeringkan tidak terbatas. Sedangkan kekurangannya sangat bergantung pada cuaca dan tidak higienis untuk bahan pangan. Kekurangan pengeringan konvensional tersebut diperkuat oleh pernyataan Hasan, $d k k$ (2014) bahwa panas yang fluktuatif mampu menurunkan kualitas bahan pangan yang dikeringkan dan memerlukan area terbuka yang luas untuk melakukan proses pengeringan bahan pangan. Begitu pula menurut Taib, $d k k$. (1987) adanya penggunaan sinar matahari, temperatur dan kelembaban yang tidak dapat dikontrol mampu menurunkan kualitas bahan yang dikeringkan. Energi biomassa merupakan salah satu sumber energi alternatif yang sangat penting dan potensial dikembangkan untuk berbagai kebutuhan. Pengembangan sumber energi biomassa seperti tempurung kelapa. Tempurung kelapa dengan mudah didapatkan karena jumlahnya yang melimpah, khususnya didaerah kabupaten Kepulauan Selayar. Bahan tersebut dapat dijadikan sebagai sumber energi alternatif. Tempurung kelapa dapat dibakar dengan efisiensi yang tinggi dengan kontrol yang mudah.

Berdasarkan

permasalahan

tersebut, diperlukan adanya upaya untuk pengembangan teknologi yang efektif, efisien dan tepat guna dalam pengeringan. Mesin pengering dengan menggunakan bahan bakar biomassa adalah salah satu contoh pemanfaatan limbah pertanian menjadi energi panas yang sangat berguna. Dengan menggunakan mesin pengering dengan bahan bakar biomassa, kita dapat mengeringkan hasil pertanian dan perkebunan tanpa menggunakan bahan bakar fosil.

\section{TUJUAN PENELITIAN}

Penelitian ini bertujuan untuk mengetahui modifikasi mesin pengering menggunakan bahan bakar tempurung kelapa dan untuk mengetahui kebutuhan 
bahan bakar selama proses pengeringan biji-bijian (gabah padi).

\section{BAHAN DAN METODE PENELITIAN}

Bentuk penelitian ini adalah penelitian rekayasa/rancangbangun, pada penelitian ini dilakukan uji performa mesin dan penggunaan bahan bakar Berikut ini adalah gambar desain produk yang akan dirancang pada penelitian ini :

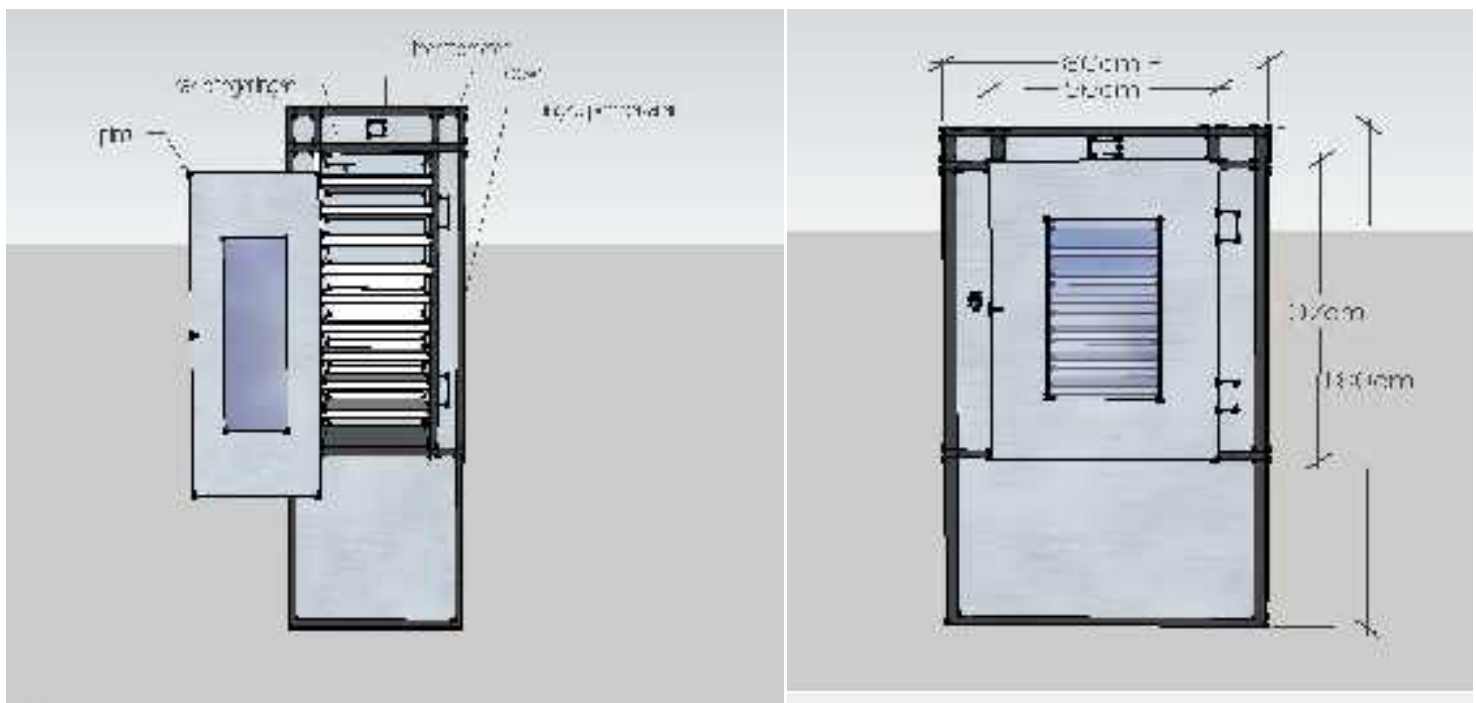

Gambar 1.

Desain Mesin pengering tampak depan

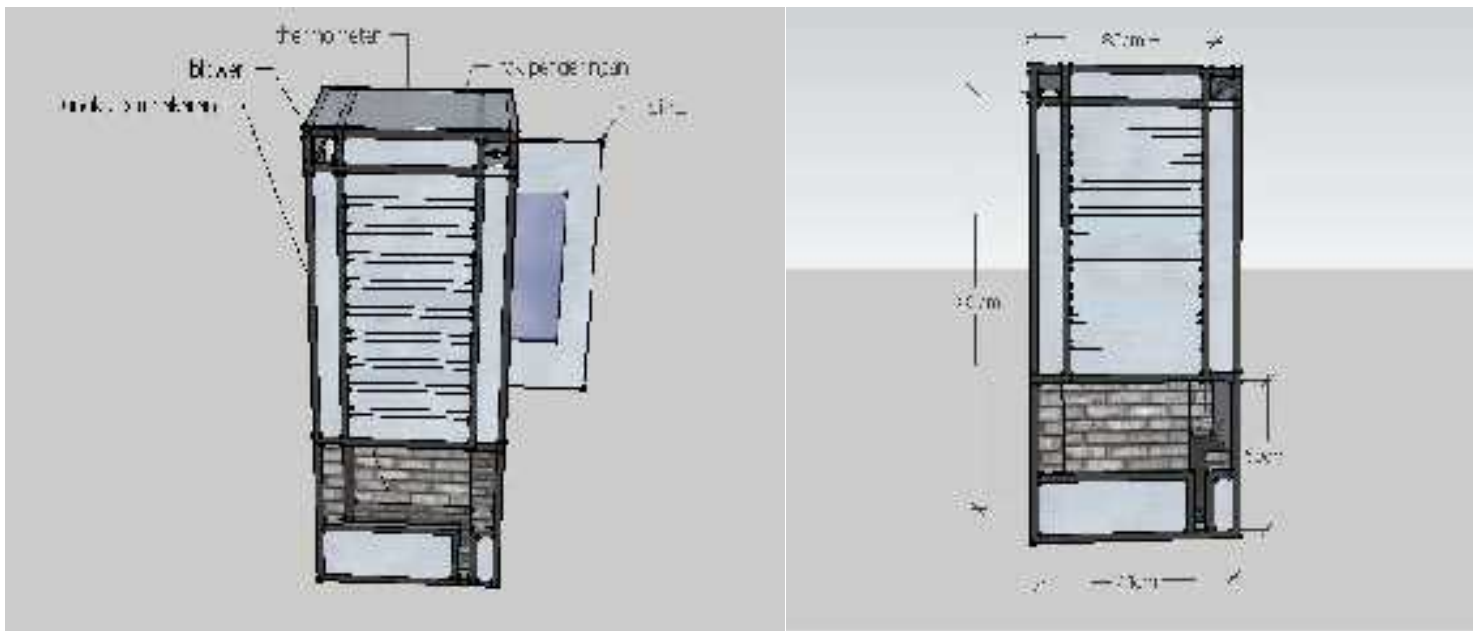

Gambar 2.

Desain Mesin pengering tampak belakang

Alat dan bahan yang digunakan dalam perancangan mesin, yaitu sebagai berikut:
1. Alat

- Mesin las

- Mesin bor

- Roll meter

- elektroda

- Palu las 
- Sikat besi

- Kacamata las

- Kaos tangan

- Blower

- Thermostat themperatur control

2. Bahan

- Besi kotak dan besi siku

- Besi plat dan seng plat

- Rang

- Batu bata dan campuran semen

- Kabel

- Engsel

Prosedur perancangan pada penelitian ini dilakukan dengan prosedur sebagai berikut :

1. Potong besi sesuai dengan dimensi yang telah direncanakan. Setelah itu rangkaikan sehingga menjadi rangka mesin pengering.

2. Potong seng plat sesuai dengan dimensi yang telah direncanakan. Setelah itu pasang pada sisi-sisi rangka mesin pengering yang sudah dibuat sebelumnya. Pada bagian depan (pintu) dipasang kaca transparan dengan tujuan agar bahan yang dikeringkan dapat terlihat dari luar.

3. Pasang blower pada bagian atas mesin pengering yang bertujuan untuk menghisap udara panas yang ada pada ruang pengering agar udara panas yang ada pada ruang pengering terus berganti dan thermostat themperature control untuk mengatur suhu.

4. Buat tungku pembakaran dari batu bata dengan campuran semen pada bagian bawah tempat terjadinya pembakaran tempurung kelapa. Pada bagian atas tungku antara tungku dengan ruang pengring dipasang plat besi untuk menghambat panas yang berlebih.
5. Setelah semua komponen mesin jadi, rangkaikan blower, tungku pembakaran, thermostat themperature control dan ruang pengering

Pengujian dilakukan dengan beberapa tahap, yaitu:

1. Pengujian limbah tempurung kelapa dengan membakarnya didalam tungku, kemudian udara panas ke ruang pengering.

2. Mengukur kadar air awal gabah padi sebelum dikeringkan

3. Memasukkan gabah padi yang akan dikeringkan

4. Menganalisa pembakaran limbah tempurung kelapa selama proses pengeringan berlangsung.

5. Menghitung jumlah tempung kelapa ( $\mathrm{kg} /$ menit) yang habis dibakar dan lama waktu proses pengeringan biji-bijian.

6. Mengukur kadar air akhir gabah padi setelah dikeringkan

7. Mengumpulkan data-data yang sudah didapat.

Teknik analisis data yang digunakan pada penelitian ini adalah teknik analisis data kuantitatif dengan statistik deskriptif, data yang diperoleh ditabulasikan ke dalam bentuk tabel dan diinterpretasikan melalui grafik yang kemudian akan menjadi acuan dalam membuat deskripsi mengenai uji kerja dari mesin. Pengujian pada penelitian ini hanya terbatas pada uji kerja mesin sehingga data yang disajikan dalam penelitian ini adalah bentuk data rasio yang diperoleh dari hasil pengukuran.

\section{HASIL DAN PEMBAHASAN}

\section{Deskripsi Produk yang Dihasilkan}

Proses perancangan alat mesin pengering biji-bijian dengan bahan bakar tempurung kelapa pada penelitian ini 
terdapat 3 tahap yaitu: pembuatan rangka, membuat rangkaian thermometer dan kipas, pembuatan tungku finalisasi.

Pembuatan rangka alat mesin pengering biji-bijian dengan bahan bakar tempurung kelapa mengacu pada gambar desain yang telah dibuat. Kemudian menyiapkan alat dan bahan, mengukur bahan yang digunakan, memotong bahan, dan merangkai komponen-komponen rangka.

Potongan rangka yang dibuat terdiri dari rangka samping kiri, tengan dan kanan yang terdiri dari 24 potongan rangka utama, yaitu 12 potongan rangka luar dengan ukuran masing-masing panjang $\mathrm{x}$ lebar $\mathrm{x}$ tinggi adalah $80 \mathrm{~cm}$ x $60 \mathrm{~cm} \times 180 \mathrm{~cm}, 12$ potong rangka pada bagian ruang pengering hingga tungku terbentuk dengan 2 ukuran yang berbeda, 8 potongan rangka horizontal dengan ukuran $56 \mathrm{~cm}$, sedangkang 4 potongan rang vertikal dengan ukuran 110 $\mathrm{cm}$. Selebihnya potongan kecil untuk memperkokoh mesin pengering. Kemudian pemotongan plat besi untuk ruang pengering, bagian luar dari mesin pengering dan wadah pengering.

Potongan-potongan yang akan dirangkai adalah 24 potongan rangka utama yang terdiri berbagai ukuran. Rangka yang pertama adalah rangka pada bagian luar yang membentuk persegi panjang, kemudian rangka bagian dalam yaitu pada ruang pengering hingga tungku. Langkah selanjutnya adalah pemasangan plat besi yang sudah dipotong pada bagian dalam dari mesin pengering.

Langkah selanjutnya pemasangan stan pada rak pengering, sebagai dudukan dari wadah pengering. Bahan yang digunakan adalah besi siku ukuran $4 \times 4$ dipotong dengan ukuran $50 \mathrm{~cm}$, kemudian dipasang pada bagian ruang pengering antara lubang sirkulasi udara dengan jarak $10 \mathrm{~cm}$.

Wadah pengering dibuat dari bahan besi plat, dengan ukuran $60 \mathrm{~cm} \times 50 \mathrm{~cm} \times 5$ $\mathrm{cm}$. Besi plat dipotong sesuai ukuran $65 \mathrm{~cm}$ x $55 \mathrm{~cm}$ kemudian ukur $5 \mathrm{~cm}$ masingmasing dari pinggir untuk dilipat, sehingga membentuk sebuah wadah pengering berbentuk persegi.

Pintu pengering dibuat dari bahan rangka besi holo $3 \times 3$ dan besi plat dengan ukuran $110 \mathrm{~cm}$ x $67 \mathrm{~cm}$. Pintu ini dilengkapi dengan kaca transparan $10 \mathrm{~mm}$ dan karet pada bagian dalam pintu yang mengelilingi sudut pintu, bertujuan untuk menghambat udara panas yang nantinya keluar pada sela-sela pintu.

Termometer yang digunakan adalah termometer kontrol digital. Adapun komponen yang dibutuhkan untuk rangkaian ini yaitu 1 digital temperature controller PID BERME Rex C 100, $1 \mathrm{~K}$ thermocoupel, 1 SSR 25A kabel detektor, kabel warna merah dan hitam masing-masing 3 meter, terminal kabel, kabel serabut, steker, lampu LED, dan fan motor axial blower 60x80.

Bahan yang digunakan dalam pembuatan tungku ini adalah campuran semen dan pasir, batu bata merah,dan air. Sedangkan alat yang digunakan adalah sendok semen dan sekop. Tungku dipasang pada bagian bawah ruang pengering, dilengkapi 2 pintu untuk memasukkan bahan bakar dan untuk mengeluarkan sisa pembakaran setelah selesai melakukan pengeringan.

Pada gambar 3 sampai gambar 6 Berikut ini adalah deskripsi pembuatan mesin pengering yang dihasilkan. 


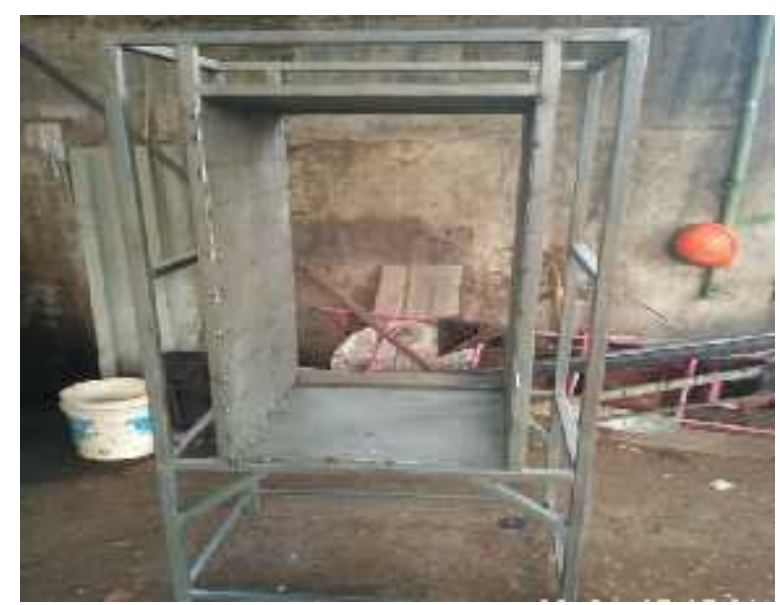

Gambar 3.

Rangka Mesin Pengering

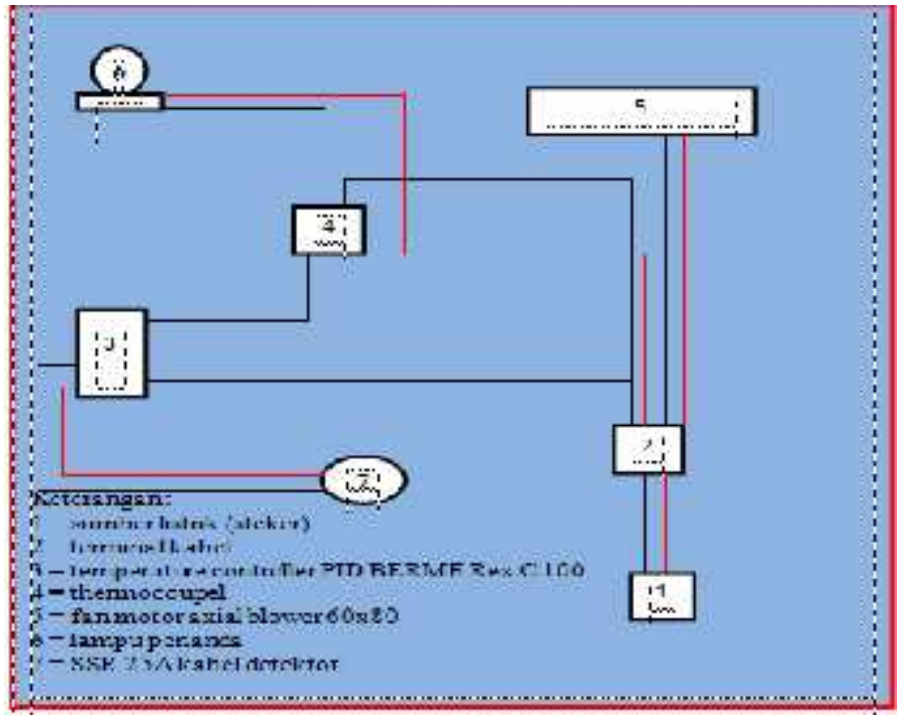

Gambar 4.

Rangkaian Termometer dan Kipas

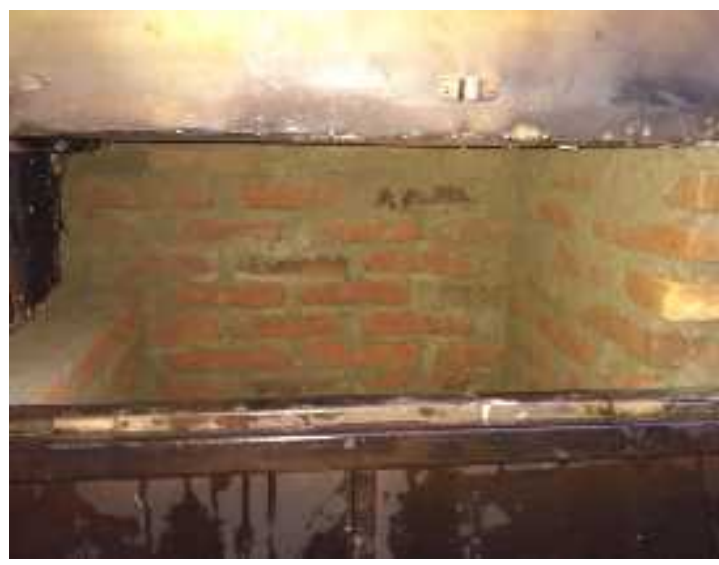

Gambar 5.

Pembuatan Tungku Pembakaran 


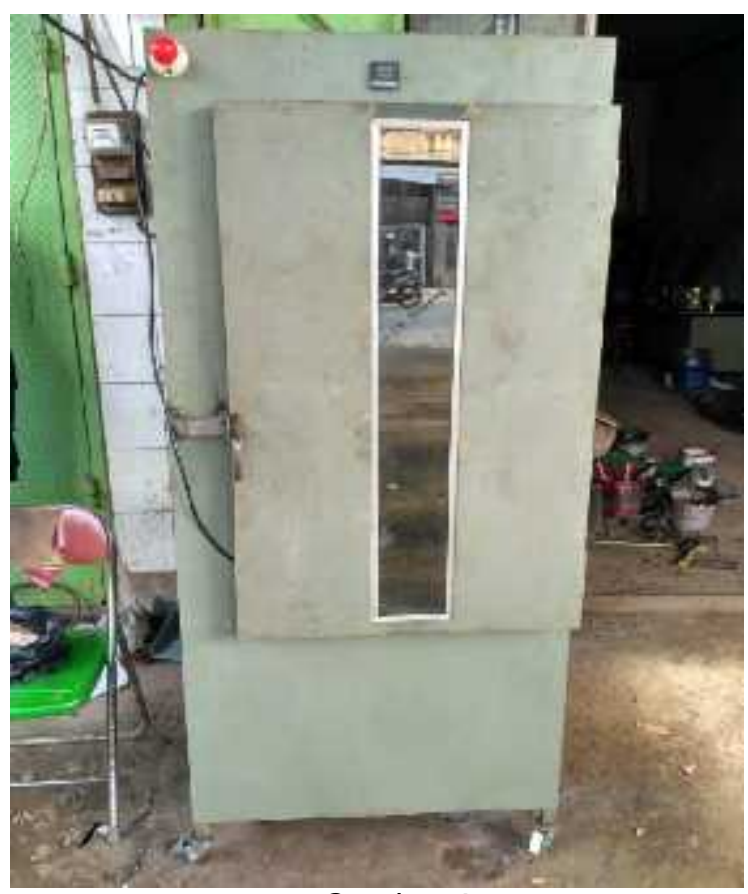

Gambar 6.

Mesin Pengering Siap Digunakan

Tahap finalisasi dalam pembuatan alat mesin pengering ini adalah pemasangan thermostat themperature control pada bagian atas mesin dan lampu penanda panas. Ada beberapa komponen yang dibutuhkan yaitu yaitu 1 digital temperature controller PID BERME Rex C 100, $1 \mathrm{~K}$ thermocoupel, 1 SSR 25A kabel detektor, kabel warna putih dan hitam masing-masing 3 meter, stop kontak, kabel serabut, steker, lampu LED. Setelah semua komponen dirangkai, mesin siap dioperasikan dapat dilihat pada gambar 6

\section{Spesifikasi Mesin Pengering}

Adapun spesifikasi dari mesin pengering bahan bahan bakar tempurung kelapa adalah sebagai berikut:
a. Type :Rak
b. Kapasitas : $27 \mathrm{~kg} /$ proses
c. Produk : Padi, jagung, kedelai, kopi, dll
d. Bahan Bakar:Tempurung kelapa, kayu bakar, bisa menggunakan LPG

e. Penuerunan Kadar Air :1-3 \%/jam

f. Kontrol Suhu :Manual

g. Dimensi Mesin $\quad: 1800 \times 800 \times 600 \mathrm{~mm}$

h. Ruang Bahan bakar :800x600x600 mm

i. Material yang Digunakan :
1) Plat Besi
: 1-2 mm
2) Besi Kotak
$: 3 \times 3 \mathrm{~cm}$
3) Besi Siku
$: 4 \times 4 \mathrm{~cm}$
4) Blower
: Axial

\section{Konsumsi Bahan Bakar}

Berdasarkan hasil pengamatan dan perjitungan, konsumsi bahan bakar alat mesin pengering biji-bijian dengan bahan bakar tempurung kelapa dapat dilihat pada gambar 7 berikut. Pada gambar Menunjukkan bahwa semakin lama pengeringan, semakin sedikit konsumsi tempurung kelapa yang dibakar. Suhu yang digunakan dalam pengeringan ini adalah $60^{\circ}$ $C$ dengan pembakaran awal bahan bakar pada tungku sebanyak $3 \mathrm{~kg}$ tempurung kelapa. Dari menit 10 sampai 20, dilakukan penambahan tempurung kelapa sebanyak 2 
$\mathrm{kg}$, kemudian 10 menit berikutnya dilakukan penambahan $1 \mathrm{~kg}$. Ini disebabkan karena cepatnya penurunan suhu pada ruang pengering, setelah terjadi penumpukan arang tempurung, penambahan dikurangi menjadi $0,5 \mathrm{~kg}$ dari menit 20 hingga menit 100. Kemudian penambahan selanjutnya sesuai dengan kebutuhan suhu pada ruang pengering. Lama pengeringan adalah 240 menit.

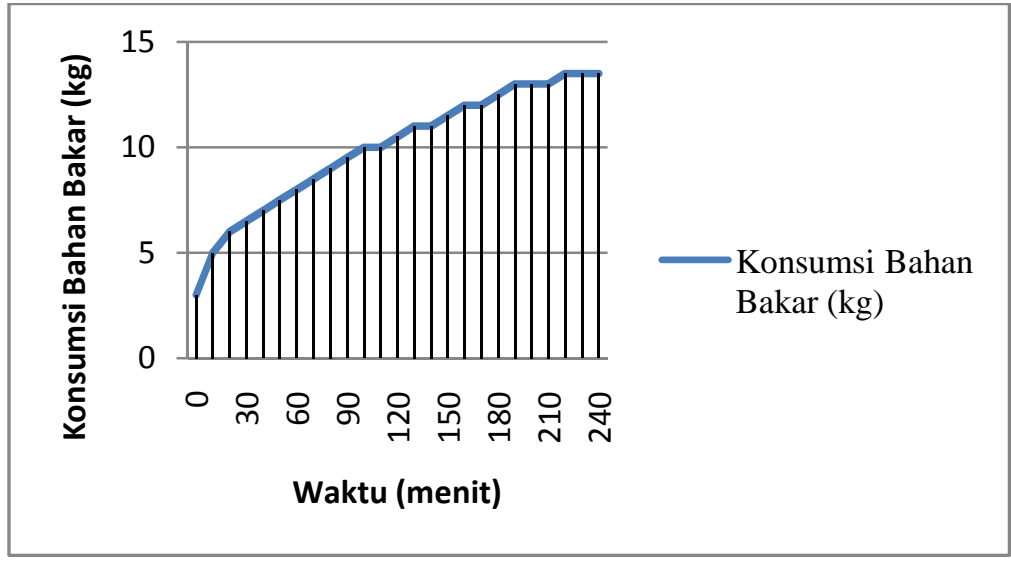

Gambar 7

Konsumsi Bahan Bakar

Penambahan bahan bakar dilakukan sedikit demi sedikit, jika suhu masih turun dari $60^{\circ} \mathrm{C}$ pada termometer maka dilakukan penambahan $1 / 2 \mathrm{~kg}$, maka akan kembali pada suhu yang diinginkan. Setelah pengeringan selama 2 jam penambahan bahan bakar dikurangi karena banyaknya tumpukan arang tempurung yang masih menghasilkan panas.

Suhu dalam ruang pengering tidak seragam, bagian bawah dari yang terdekat dengan sumber panas adalah yang paling tinggi, diikuti oleh bagian atas dan bagian tengah. Suhu rata-rata ruang pengering bagian bawah mencapai $70^{\circ} \mathrm{C}$, diikuti oleh bagian atas $65^{\circ} \mathrm{C}$, dan bagian tengah $60^{\circ}$ C.Berdasarkan penelitian yang dilakukan Triyono, dkk. (2008) sedikit berbeda dengan penelitian ini. Dimana suhu rata-rata ruang pengering bagian bawah mencapai $66^{\circ} \mathrm{C}$, diikuti bagian tengah $57^{\circ} \mathrm{C}$, dan bagian atas $54^{\circ} \mathrm{C}$. Menurut Mursilam (1995) dalam Karwito (1998) menyebutkan perbedaan suhu pada masing-masing rak sangat dipengaruhi oleh aliran udara. Aliran udara yang tidak merata akan menyebabkan distribusi suhu yang tidak merata pula.

Pengamtan mencatat bahwa suhu dalam ruang pengering bisa mencapai lebih dari $70^{\circ} \mathrm{C}$, akan tetapi bisa merusak dari bahan yang dikeringkan. Hal ini berarti kecepatan pengeringan masih dapat ditingkatkan dengan cara membesarkan nyala api yang disertai dengan penambahan kipas hisap pada bagian atas ruang mesin pengering.Karena suhu dalam ruang pengering berbeda-beda, lama waktu pengeringan dari rak 1 sampai 9 berbeda. Dari hasil pengujian kadar air, rak 8 dan 9 yang terletak pada bagian paling bawah sudah kering dalam waktu 150 menit disusul rak 1 dan 2 dalam waktu 180 menit, secara keseluruhan kering dalam waktu 240 menit dengan kadar air yang berbeda. Distribusi suhu pada alat pengering tipe rak memiliki kecenderungan suhu tertinggi terjadi pada rak bagian paling atas dan bawah yang diakibat oleh adanya perpindahan panas 
tambahan dari sisi atap lemari pengering (Mursalim, 1995 dalam Karwito 1998).

Kadar Air awal dan Kadar Air Akhir
Jumlah penurunan kadar air dari gabah basah baru dipanen hingga kering dapat dihat pada Tabel 1 Berikut

Tabel. 1

Kadar air awal dan akhir gabah

\begin{tabular}{|c|c|c|c|}
\hline No. & RakJ Wadah & Kadar air awal (\%) & Kedar air akhir (\%) \\
\hline $\mathbf{1}$ & 9 & 23 & 12,7 \\
\hline $\mathbf{2}$ & $\mathbf{8}$ & 23,5 & 13,8 \\
$\mathbf{3}$ & $\mathbf{7}$ & 24,1 & 13,8 \\
\hline $\mathbf{4}$ & 6 & 23,4 & 14,3 \\
\hline $\mathbf{5}$ & 5 & 23,4 & 14 \\
\hline $\mathbf{6}$ & 4 & 24,4 & 14,2 \\
\hline $\mathbf{7}$ & 3 & 23,1 & 11,3 \\
\hline $\mathbf{8}$ & 2 & 23,1 & 10,9 \\
\hline $\mathbf{9}$ & 1 & 23,1 & 9,9 \\
\hline
\end{tabular}

Berdasarkan Tabel 1. dapat dilihat bahwa penurunan kadar air tidak seragam. Jumlah penurunan kadar air dari rak 1 sampai 9 berbeda-beda, sehingga lama pengeringan pun tidak bersamaan. Pada rak 1 dan 2 yang terletak bagian paling bawah kering lebih awal dengan waktu 150 menit, sementara rak 8 dan 9 kering dengan waktu 180 menit. Sementara rak 3, 4, 5, 6, dan 7 kering dengan waktu 240 menit. Penurunan kadar air tidak seragam disebabkan putaran blower pengisap terlalu lambat, pada rak 1 dan 2 cepat kering karena dekat dengan sumber panas, sedangkan pada rak 8 dan 9 lebih cepat kering dibandingkan rak tengah karena terjadi penumpukan panas pada rak bagian atas, ini disebabkan oleh lambatnya sirkulasi udara.

\section{Revisi Produk}

Alat mesin pengering biji-bijian dengan bahan bakar tempurung kelapa merupakan teknologi tepat guna yang masih membutuhkan banyak masukan dan perbaikan mulai dari bahan yang digunakan, model dari komponen alat sampai kinerja alat yang dihasilkan. Agar tercipta sebuah alat yang dapat digunakan pada proses pengeringan yang lebih efisien waktu dan tenaga. Alat dan bahan yang digunakan harus terjangkau dan mudah didapatkan dipasaran, sehingga bahan yang digunakan harus dapat diefisiensikan untuk menghemat biaya produksi.

\section{Kajian Produk Akhir}

Produk akhir pada penelitian rancang bangun ini adalah tercipta sebuah alat mesin pengering dengan memanfaatkan limbah tempurung kelapa sebagai bahan bakar. Fungsi dari alat ini yaitu sebagai alat pengering berbagai jenis biji-bijian.

Beberapa keunggulan dari alat ini yaitu sebagai alternatif pengeringan musim hujan maupun musim kemarau, bahan bakar yang digunakan murah bahkan bisa diperoleh secara gratis, dapat mempercepat proses pengeringan, dapat menghemat tenaga kerja. Kekurangan alat ini yaitu pada saat pengeringan, bahan bakar dikontrol secara manual jadi harus hati-hati dan untuk 
keamaman disarankan memakai kaos tangan.

\section{KESIMPULAN}

Kesimpulan penelitian ini adalah sebagai berikut:

1. Modifikasi mesin pengering biji-bijian dimodifikasi pada bagian sumber panas, yang sebelumnya menggunakan gas LPG diganti menjadi tungku pembakaran dengan bahan bakar yang digunakan adalah tempurung kelapa.

2. Bahan bakar yang diperlukan untuk mengeringkan $18 \mathrm{~kg}$ gabah basah diperlukan sebanyak $13,5 \mathrm{~kg}$ tempurung kelapa dengan lama pengeringan 240 menit.

\section{SARAN}

Untuk pembuatan mesin pengering semacam ini selanjutnya, sebaiknya jangan menggunakan plat besi yang tipis sebagai bahan dindingnya. Karena menimbulkan panas yang berlebihan ketika proses pengeringan berlansung. Bila perlu lapisi glasswol pada dinding untuk menghambat panas. Saran lain, untuk peneliti selanjutnya bisa mencoba bahan bakar alternatif kayu sebagai pengganti tempurung kelapa

\section{DAFTAR PUSTAKA}

Anonim. 2002. Inisiatif Energi Hijau. Jakarta:

Direktorat Jenderal Listrik dan Pemanfaatan Energi.

Mohsenin, 1980. Physical Properties of Plant and Animal materials. 2nd edition. Gordon and Breach Science. New York USA

Hasan, dan Abu. 2014. Modul Satuan Operasi. Polsri. Palembang
Karwito. 1998. Kajian Distribusi Aliran dan Suhu Udara dalam Model Alat Pengering. IPB, Bogor

Taib, G., G. Said., S. Wiraatmadja, (1987): Operasi Pengeringan pada Pengolahan Hasil Pertanian, Jakarta, Mediyatama Sarana Perkasa.

Triyono, S., Haryanto, A., Haryati, R.S, 2008, rancang bangun dan uji kinerja alat pengering kopra tipe rak berbahan bakar biomassa. Yogyakarta (ID): UGM. 